\title{
DEVELOPING A VR TOOL FOR 3D ARCHITECTURAL MEASUREMENTS
}

\author{
A. Papadopoulou ${ }^{1}$, D. Kontos ${ }^{1}$, A. Georgopoulos ${ }^{1}$ \\ ${ }^{1}$ Laboratory of Photogrammetry, NTUA, Greece \\ ekaterpap@gmail.com, dimitriskontos@topodomiki.gr,drag@central.ntua.gr
}

\section{Commission II}

KEY WORDS: Unreal Engine, 3D model, 3D measurements, Virtual Reality, HTC Vive ${ }^{\circledR}$

\begin{abstract}
:
Virtual Reality technology has already matured and is capable of offering impressive immersive experiences. AT the same time head mounted devices (HMD) are also offering many possibilities along with the game engine environments. So far, all these impressive technologies have been implemented to increase the popularity of on-line visits and serious games development, as far as their application in the domain of Cultural Heritage is concerned. In this paper we present the development of a set of VR tools, which enable the user to perform accurate measurements within the immersive environment. In this way we believe that these tools will be very helpful and appeal to experts in need of these measurements, as they can perform them in the laboratory instead of visiting the object itself. This toolbox includes measuring the coordinates of single points in 3D space, measuring three-dimensional distances and performing horizontal or vertical cross sections. The first two have been already presented previously (Kontos \& Georgopoulos 2020) and this paper focuses on the evaluation of the performance of the toolbox in determining cross sections. The development of the tool is explained in detail and the resulting cross sections of the 3D model of the Holy Aedicule are compared to real measurements performed geodetically. The promising results are discussed and evaluated.
\end{abstract}

\section{INTRODUCTION}

Contemporary digital methods for the geometric documentation of monuments and of buildings in general have enabled the production of three-dimensional textured models of high resolution. So far these 3D models have been used mainly for visualization purposes, for 3D printing and for virtual visits. However, the three-dimensional models carry valuable metric information, which could also be exploited, but it requires special skills and competence in using a multitude of software. In this paper we present the development of an integrated tool for performing accurate measurements in a $3 \mathrm{D}$ model within a VR environment. This tool is addressed to anybody who is able to wear a HMD and use its simple controllers, thus practically requiring no special skills.

With this tool all interested experts studying the object are able to perform measurements of three-dimensional distances, vertical and horizontal sections and determine point coordinates at will. In this paper it is shown how the 3D models are introduced into the VR environment, how the various functions of the tool have been developed and how it operates in real conditions. Finally, the results of the measurements are evaluated for their accuracy and reliability.

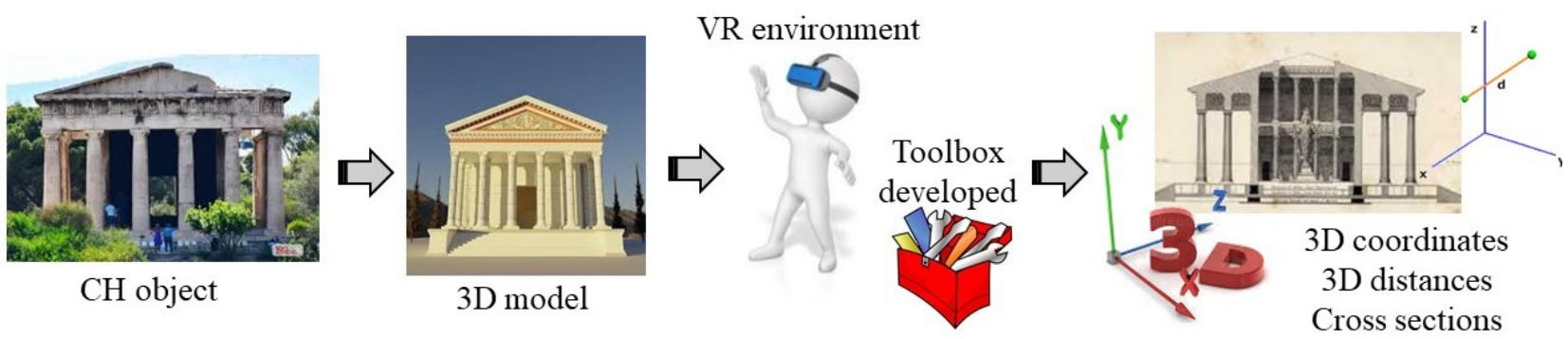

Figure 1. Schematic concept of the VR toolbox developed

\section{RELATED WORKS}

There are increasing publications on the use of VR in cultural heritage applications in the recent literature. Immersive environments can increase visitors' emotional involvement and they can also play an essential role to the study, preservation and protection of cultural sites. However, almost none of those studies mention or realize the performance of measurements in the three-dimensional models. The research on this general topic is rich in Serious Games implementations, which belong to the "edutainment" field (Thomas P. Kersten et al., 2018). Serious Games contribute to the dissemination of cultural heritage through interactive applications that stimulate interest and facilitate the understanding of historical information. In addition, VR technology has served for enabling disabled persons to visit and admire cultural heritage objects (Jiménez FernándezPalacios et al., 2017).

Similar implementation is the creation of the "Timeless Museum" (Aiello et al., 2019), which brings together exhibits situated in various parts of the world, in order to form a new concept museum. The use of VR solutions for enabling virtual visits is becoming increasingly common lately. The Photogrammetry and Laser Scanning Lab of HafenCity 
University, Hamburg, developed two interactive applications which enable users to explore the Solomon's Temple and its surrounding buildings, while providing a multi-user functionality which offers the possibility of interactive on-line discussions among visitors (Kersten et al., 2018a and 2018b). Another interesting development is the creation of an immersive environment based on the virtual city model of the town of Stade in 1620. The implementation of panorama photographs allows users to compare the historic with the modern city and examine the factors that contributed to its present form (Walmsley and Kersten, 2020). An AR application available for mobile devices, is introduced by (Scianna et al., 2020) and includes the visualization of the Wignacourt fountain in its initial position, in St. George Square in Valletta. Banfi et al. (2019) have implemented VR technology to enable the monitoring of the restoration works in Sant' Ambrogio church in Milan and present its complex historical phases. The VR simulation of Santa Maria Delle Grazie, constitutes an immersive experience, which integrates audiovisual and interactive tools, ensuring a high level of realism (Bolognesi and Aiello, 2019).

However, none of the VR applications in the literature offers the possibility to perform measurements on the $3 \mathrm{D}$ models. The virtual reality application presented in this paper augments a previously developed one (Kontos and Georgopoulos, 2020), which allowed users to perform basic topographic processes on an already created 3D model inside a virtual environment. Specifically, with the developed application the user is able to perform measurements of distances between two points in threedimensional space and measurement and extraction of the threedimensional coordinates of any point inside the virtual reality environment.

\section{HARDWARE - HTC VIVE ${ }^{\circledR}$ VR SYSTEM}

\subsection{HTC Vive ${ }^{\circledR}$}

Before the initial developing stage of the above application, market research was performed to determine which virtual reality system and which game engine is most suitable to use and finally the HTC Vive ${ }^{\circledR}$ virtual reality system and the Unreal Engine 4 game engine were used (Kontos and Georgopoulos, 2020). It should be noted that the particular system has been discontinued, but it is still available and operating.

The HTC Vive ${ }^{\circledR}$ is a VR system developed by the HTC and Valve Corporation companies. It was firstly released in April 2016. It is a virtual reality system of high cost, which can work supported by a PC running Windows, Linux or MacOS operating system. HTC Vive ${ }^{\circledR}$ has the following components (Figure 2):

- A virtual reality headset with two full high-definition OLED screens, with $90 \mathrm{~Hz}$ refresh rate for each screen and a 110 degree field of view.

- Two wireless rechargeable controllers.

- Two tracking lighthouses emitting nonvisible light in $8.333 \mathrm{~ms}$ period to trace the headset and the controllers inside the virtual room.

The above-mentioned gear is the standard equipment for an HTC Vive $^{\circledR}$ to work but there are many extra peripherals to cover the extra needs for users or developers. For this application, the basic HTC Vive ${ }^{\mathbb{B}}$ setup was used.

Practically, the HTC Vive ${ }^{\circledR}$ system defines a 3-dimensional space inside of which it tracks the headset and the joysticks. That space can be from $2 \mathrm{~m} \times 1,5 \mathrm{~m}$ minimum to $4 \mathrm{~m} \times 3 \mathrm{~m}$ maximum. A thorough research and detailed analysis of the tracking system has been done by several experts (Borges et al., 2018; Kreylos,
2016). Furthermore, the PC system requirements for HTC Vive ${ }^{\circledR}$ to function are shown in Table 1:

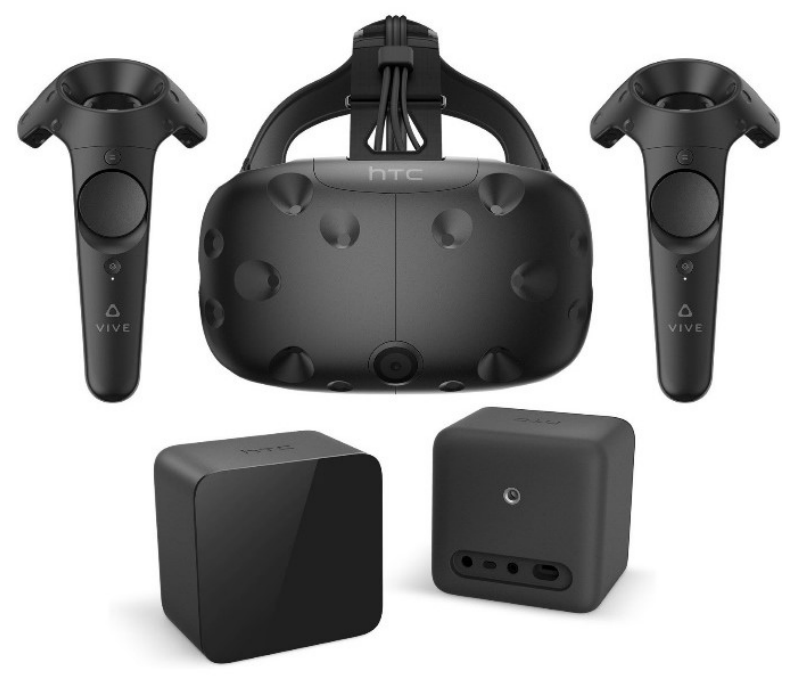

Figure 2. The basic components of the HTC Vive ${ }^{\circledR}$

Table 1. HTC Vive ${ }^{\circledR}$ minimum system requirements.

\begin{tabular}{|c|c|c|}
\hline Component & $\begin{array}{l}\text { Recommended System } \\
\text { Requirements }\end{array}$ & $\begin{array}{l}\text { Minimum System } \\
\text { Requirements }\end{array}$ \\
\hline Processor & $\begin{array}{c}\text { Intel Core i5- } \\
\text { 4590/AMD FX } 8350 \\
\text { equivalent or better }\end{array}$ & $\begin{array}{l}\text { Intel Core i5- } \\
\text { 4590/AMD FX } 8350 \\
\text { equivalent or better }\end{array}$ \\
\hline GPU & $\begin{array}{c}\text { NVIDIA GeForce GT } \\
\text { X } \\
\text { 1060, AMD Radeon R } \\
\text { X } 480 \text { equivalent or } \\
\text { better }\end{array}$ & $\begin{array}{l}\text { NVIDIA GeForce GTX } \\
970 \text {, AMD Radeon R9 } \\
290 \text { equivalent or better }\end{array}$ \\
\hline Memory & 4 GB RAM or more & 4 GB RAM or more \\
\hline $\begin{array}{l}\text { Video } \\
\text { Output }\end{array}$ & $\begin{array}{c}\text { HDMI } \\
\text { 1.4, DisplayPort } 1.2 \text { or } \\
\text { newer }\end{array}$ & $\begin{array}{c}\text { HDMI } \\
\text { 1.4, DisplayPort } 1.2 \text { or } \\
\text { newer }\end{array}$ \\
\hline USB port & $1 \mathrm{x}$ USB 2.0 or newer & 1x USB 2.0 or newer \\
\hline $\begin{array}{l}\text { Operating } \\
\text { System }\end{array}$ & $\begin{array}{l}\text { Windows } 7 \\
\text { SP1, Windows } 8.1 \text { or } \\
\text { later, Windows } 10 \text {, } \\
\text { Linux or MacOS }\end{array}$ & $\begin{array}{c}\text { Windows } 7 \\
\text { SP1, Windows } 8.1 \text { or } \\
\text { later, Windows } 10, \\
\text { Linux or MacOS }\end{array}$ \\
\hline
\end{tabular}

HTC Vive, despite its age, can still support all kinds of applications. In addition, the system cooperates with the game engine software in which the application was developed. To conclude, taking into account all the above, the HTC Vive ${ }^{\circledR}$ was chosen, as it had the advantage of better support and documentation and the provision of virtual reality experiences at room scale.

\subsection{Controllers' visualization}

A very important element for achieving a great degree of immersion, when using the application is the realistic visualization of the HTC Vive's ${ }^{\circledR}$ controllers so that the user can "see" them in the digital environment, can understand their buttons and interact with them. A realistic free to use model of the controller was obtained on-line (www.sketchfab.com). Also, 
because the right and left controllers are identical, the texture of the right one was colored green and the left one red (Figure 3).
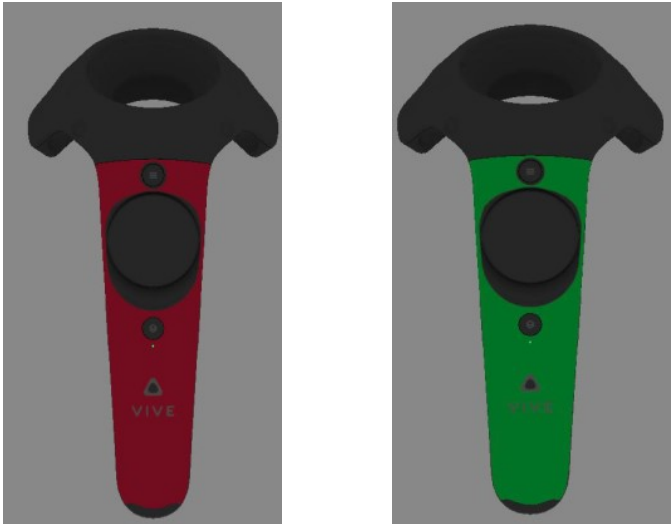

Figure 3. The final model of each controller

Through suitable programming the controllers allowed the user to move freely in the VR environment, but also to perform the measurement actions (Kontos and Georgopoulos, 2020). Consequently, their use was enhanced for the present work by adding new actions for the user.

\section{DEVELOPED METHODOLOGY}

The VR measurement tool has been developed within the Unreal Engine ${ }^{\circledR}$ v.4 (UE4) environment. Unreal Engine is a fully functional freeware game engine, which provides many parameterization features for the developer, enabling the use of user-friendly visual programming tools, called blueprints, for developing an application solely inside the game engine's environment.

As already mentioned, this work is integrating the previously developed tool for extracting point coordinates and threedimensional distances from a 3D model within a VR environment (Kontos and Georgopoulos, 2020).

\subsection{The 3D model used}

The 3D textured model of the Holy Aedicule which was created during its full rehabilitation process conducted by the NTUA's Interdisciplinary team (Georgopoulos et al., 2017; Moropoulou et al., 2017; Moropoulou and Korres, 2017) was used for testing and evaluation of the developed functions of both applications. The above-mentioned 3D model was created combining photogrammetric and laser scanning methods therefore it is highly detailed and accurate, containing 35.414.290 triangles and being textured with high resolution (Figures 4 and 5). The main problems addressed were (i) to enable the user to accurately define horizontal and vertical planes in specific positions and thus extract desired sections from the 3D model and (ii) to tackle the millions of triangles of the high-resolution model.

\subsection{Importing and positioning the 3D model}

Importing a 3D model inside an UE4 project is a rather straightforward procedure with easy steps. In this case, though, due to the complexity of the 3D model, which was going to be used, it was necessary to manipulate it to import it correctly. Two problems had to be tackled. The first problem was the unification of the various 3D model chunks with texture and the second was the transformation of the model's reference system to the local UE4 project reference system. Specifically, the transformation was realized by moving each chunk by -80 meters on the $\mathrm{X}$ axis, by -110 meters on the $\mathrm{Y}$ axis and by -760 meters on the $\mathrm{Z}$ axis and moved the model close to the $(0,0,0)$ point of the UE4 project. In addition, the relative position of each chunk with every other one was maintained. Afterwards, each chunk was imported separately into the project and then all chunks were grouped together to perform as one entity. Furthermore, final position adjustments were made manually through the tools that the UE4 provides to force the structure touch the terrain surface (Figure 6). Finally, the unified object's textured was parameterized to be independent of light sources inside the virtual environment because during the initial tests the external light sources downgraded its detail level (Kontos and Georgopoulos, 2020).
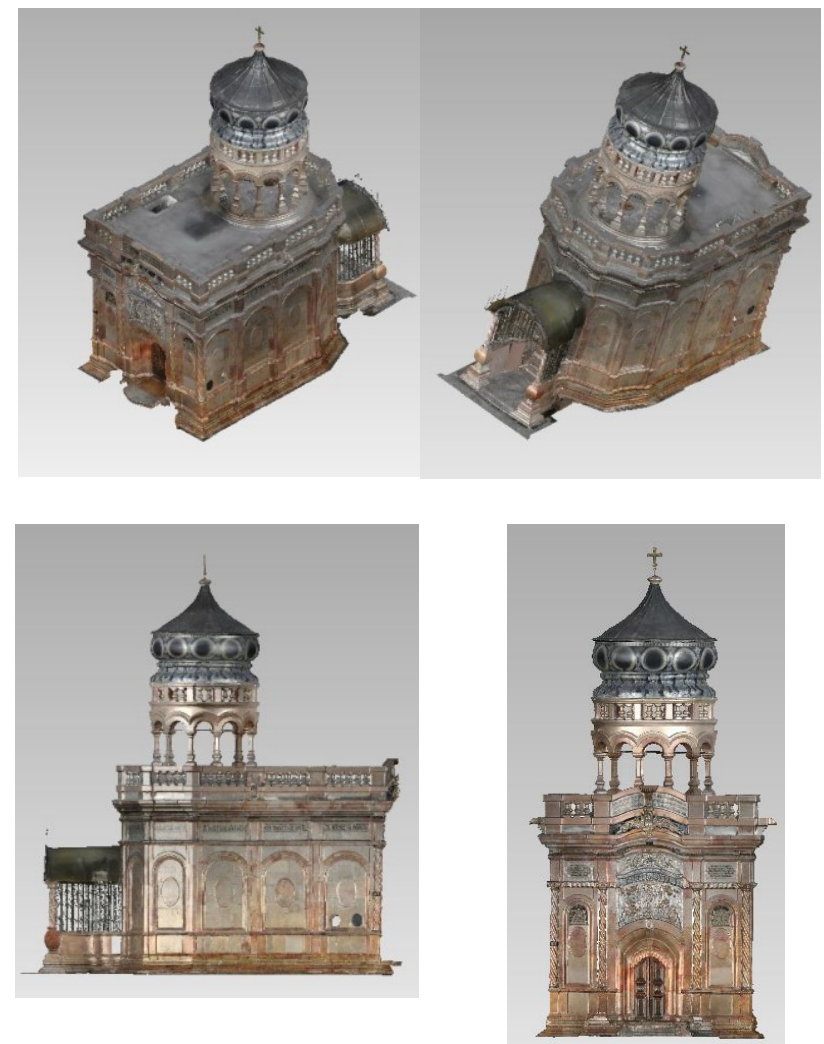

Figure 4. The exterior of the 3D model of the Holy Aedicule of the Tomb of Christ in Jerusalem from various angles
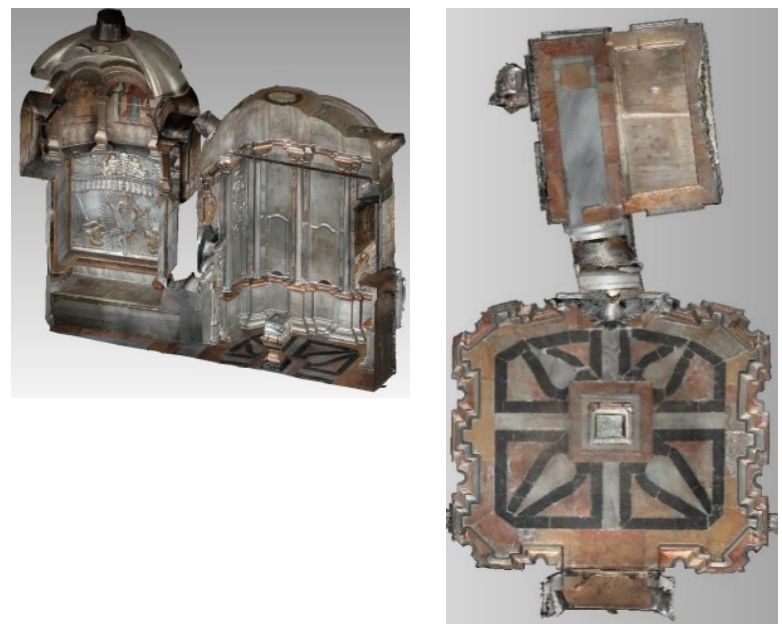

Figure 5. Vertical and horizontal sections of the 3D model showing its interior 


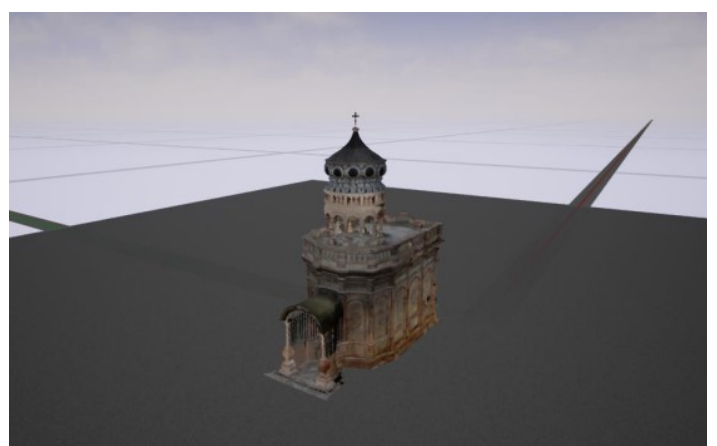

Figure 6. The final placement of the 3D model inside the virtual environment

\subsection{New functions developed}

Two different approaches were developed with suitable programming via the blueprints for the realization of the new tools.

Firstly, the user uses the motion controllers to "cut" the 3D model in order to create a horizontal or vertical slice of variable thickness between them. This is done by shooting an invisible projectile towards its surface at two hit points which define the thickness of the slice. This thickness value depends on the density of the mesh and should be carefully selected to ensure that enough information of the object's surface is included in the slice. From this slice, the user selects the points of the section that is going to be extracted.

This was performed by developing six functions, each of which defines the direction of the section and the part of the model which will become invisible. These are:

- Slice HU and Slice HD: The model is cut horizontally, and the upper (or lower) part becomes invisible.

- Slice VR and Slice VL: The model is cut parallelly to XZ plane and the part lying to the positive (or negative) side of $\mathrm{Y}$ axis becomes invisible.

- Slice_VF and Slice_VB: The model is cut parallelly to YZ plane and the part lying to the positive (or negative) side of $\mathrm{X}$ axis becomes invisible.

The functionality of this section tool was successfully evaluated using the 3D model of a simple cube (Figure 7).

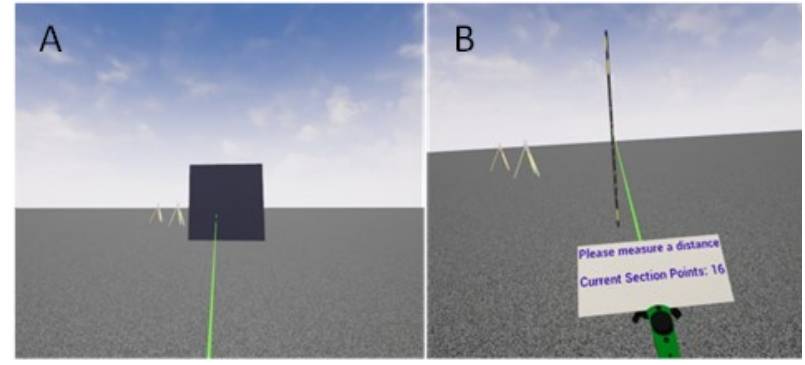

Figure 7. (A) The 3D model of a cube as a test object, (B) A vertical slice of the 3D model of a cube

The 3D model needed to be further decimated, to be easily manageable, maintaining, at the same time, a high level of realism. It is important to mention that the maximum number of polygons that UE4 can tackle depends, of course, on the computer hardware. For this reason, the model was imported into Geomagic Wrap, for reduction of the number of its triangles without losing too much detail. The 3D model was successfully imported into UE4, only after the reduction of its triangles to $5 \%$ of the initial number. However, even in this case, the application was malfunctioning, probably because of the multiple interventions, which took place in the initial project, such as the deletion of the initial 3D model and the attempts of importing downsized models into it. Hence, deletion of the initial 3D model was necessary and attempts of importing downsized models into it, led to a manageable UE4 project.
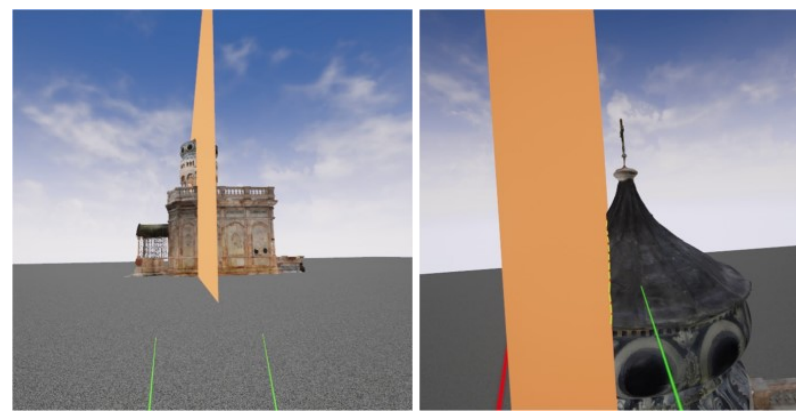

Figure 8. A vertical plane of a section defined by the user

The second method offered a solution to the above-mentioned problems, as it does not require the merging of the model's parts, and it was successfully tested on the 3D model of the Holy Aedicule without optimization process. Thus, it can probably be applied to any additional model. In this case, the user can define horizontal and vertical planes of zero thickness which "cut" both the interior and the exterior surfaces the object represented with the 3D model (Figure 8). The center of each plane is identical to the hit point of the line trace on the model's surface.
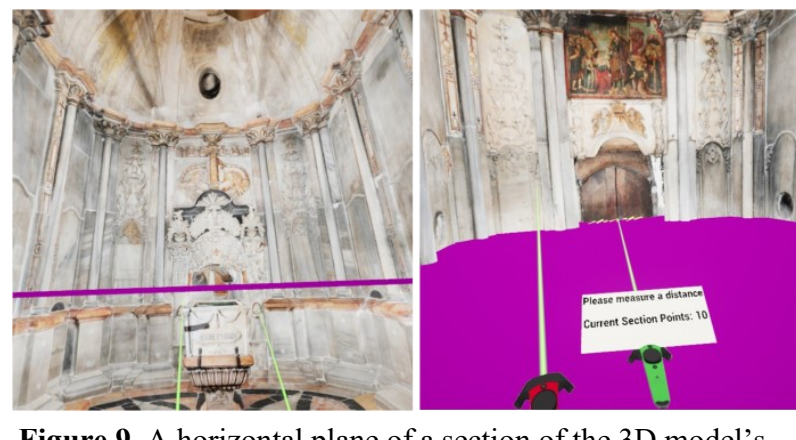

Figure 9. A horizontal plane of a section of the 3D model's interior surface

Three additional functions were developed within the game engine, defining the direction of the plane and enabling the user to extract a horizontal or vertical slice (Figure 9). These are:

- MakePlaneXY: The model is cut horizontally.

- MakePlaneXZ: The model is cut by a plane parallel to XZ plane (Figure 2).

- MakePlaneYZ: The model is cut by a plane parallel to YZ plane.

\section{EVALUATION PROCEDURE}

The VR measuring tool has been extensively tested and evaluated mainly in terms of accuracy, by estimating the correspondence of the section points extracted from the application, to points on the reference surface, i.e., the surface of the 3D model used. For this reason, both the external and the internal part of 4 sections measured traditionally, i.e., using a total station for the geometric documentation of the object (Moropoulou et al., 2017; 
Moropoulou and Korres, 2017), were also determined inside the VR environment and 7 sparse point clouds of the produced slices, inside and outside of the 3D model, were exported.

In order to determine the accuracy of the measured sections, a coordinate system transformation was necessary, from the UE4 project reference system, into the model's reference system. This is because of the inverse transformation which took place during the import of the 3D model into UE4 and its manual position adjustments, in order to define its position on the terrain surface, close to the center of the application's coordinate system (Kontos and Georgopoulos, 2020).

Specifically, the measured point clouds were mirrored over $\mathrm{XZ}$ plane, and then, a distinct point of the model's surface which was measured in both coordinate systems, was selected as an accurate transformation point (Kontos and Georgopoulos, 2020). It is worth mentioning that this procedure introduces errors into the measurements, such as the error of the user's selection of the identical point and the error of the measuring tool, which depends on the predefined thickness of the line trace. On the other hand, transformation parameters do not seem to introduce errors into the whole process. This system transformation is necessary as the initial change of reference systems was mandatory for introducing the $3 \mathrm{D}$ model into the VR environment. It is estimated that the error introduced with this reverse procedure is no more than a few millimeters.

After the above transformation, the point clouds of the two sections were imported into a suitable software (CloudCompare $^{\mathscr{C}}$ ) to calculate their differences, i.e., the distances of the geodetically measured points from the model's surface.

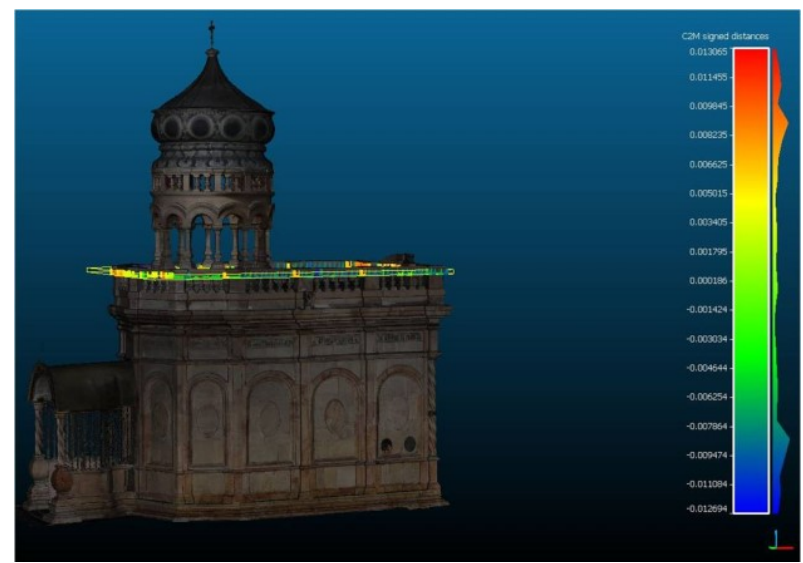

Figure 10. The $1^{\text {st }}$ horizontal section and its deviations from the reference surface

The $1^{\text {st }}$ horizontal section has no internal part, as it was performed on the balustrades of the roof, at the exterior surface of the $3 \mathrm{D}$ model used (Figure 10). This section consists of 668 points and their deviations from the reference surface range from $-12 \mathrm{~mm}$ to $13 \mathrm{~mm}$. The values with the highest frequency of occurrence are close to $\pm 9 \mathrm{~mm}$. The deviations of the $2^{\text {nd }}$ horizontal section are distributed from $-14 \mathrm{~mm}$ to $12 \mathrm{~mm}$, with some outliers exceeding $5 \mathrm{~mm}$ in absolute value (Figure 11). These outliers probably occur because of the user's inadvertent selection of points, inside the VR environment, which do not belong to the model's surface. In the histogram of this section, the most frequent values are those close to $\pm 1 \mathrm{~mm}$. The histogram of the external part is similar to the above, with the majority of the values ranging between $14 \mathrm{~mm}$ and $14 \mathrm{~mm}$, while the deviations of the corresponding internal section range from $-12 \mathrm{~mm}$ to $12 \mathrm{~mm}$, while most of them are detected close to the limits of this interval.

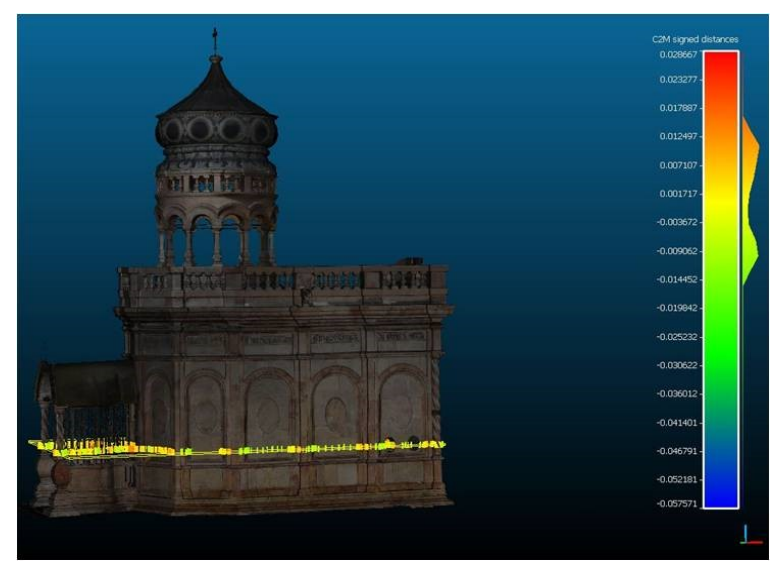

Figure 11. The $2^{\text {nd }}$ horizontal section and its deviations from the reference surface

The $1^{\text {st }}$ vertical section contains 509 points and their distances from the "true" section vary from $-13 \mathrm{~mm}$ to $12 \mathrm{~mm}$ (Figure 12). The values with the highest frequency of occurrence are those from $10 \mathrm{~mm}$ to $-8 \mathrm{~mm}$ and from $8 \mathrm{~mm}$ to $9 \mathrm{~mm}$. The same range is also observed in the external section's deviations, while the distances of the corresponding internal section from the 3D model's surface, range from $-12 \mathrm{~mm}$ to $11 \mathrm{~mm}$, with most of them lying close to the limits of this interval. According to the above, the deviations of the external and internal sections are similar. Finally, the $2^{\text {nd }}$ vertical section consists of 1088 points and their distances from the reference surface are distributed from $-12 \mathrm{~mm}$ to $10 \mathrm{~mm}$ (Figure 13). There are also some outliers detected, which reach up to $-60 \mathrm{~mm}$, most probably due to the inadvertent measurement of points close to the model's surface. Most frequent values in this histogram belong to the following intervals: $\{-10 \mathrm{~mm},-8 \mathrm{~mm}\}$, and $\{8 \mathrm{~mm}, 10 \mathrm{~mm}\}$. The values of the arithmetic mean and the standard deviation of each section are presented in Table 1 .

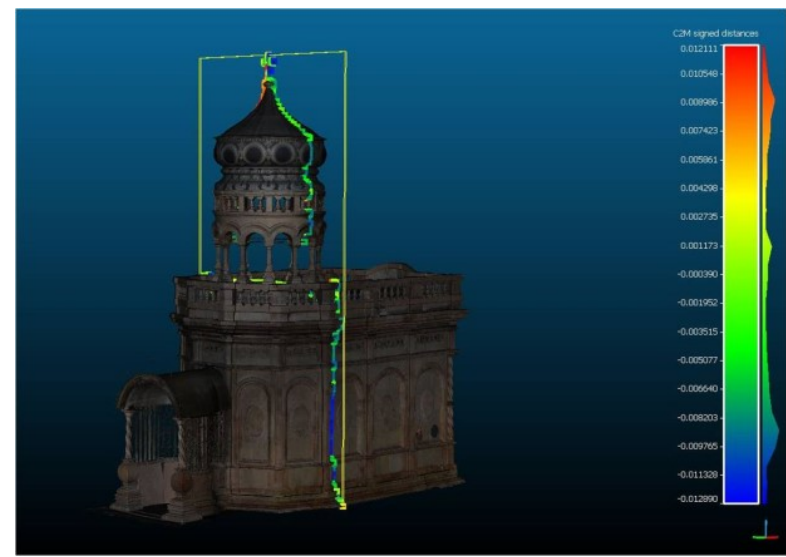

Figure 12: The $1^{\text {st }}$ vertical section and its deviations from the 3D model's surface

Table 1. Results of comparison of sections

\begin{tabular}{|c|c|c|c|}
\hline Sections & $\begin{array}{c}\text { Number } \\
\text { of points }\end{array}$ & $\begin{array}{c}\text { Mean } \\
(\mathbf{m m})\end{array}$ & $\begin{array}{c}\text { Standard } \\
\text { Deviation } \\
(\mathbf{m m})\end{array}$ \\
\hline $1^{\text {st }}$ horizontal & 668 & -0.2 & 8 \\
\hline $2^{\text {nd }}$ horizontal external & 552 & 0.4 & 9 \\
\hline $2^{\text {nd }}$ horizontal internal & 311 & -0.4 & 9 \\
\hline $1^{\text {st }}$ vertical external & 509 & -0.7 & 7 \\
\hline $1^{\text {st }}$ vertical internal & 198 & -1 & 8 \\
\hline $2^{\text {nd }}$ vertical external & 636 & -0.9 & 7 \\
\hline $2^{\text {nd }}$ vertical internal & 452 & -0.1 & 7 \\
\hline
\end{tabular}




\section{DISCUSSION OF RESULTS}

It should be noted that in the histograms of the sections, the values with the highest frequency of occurrence are close to $\pm 9 \mathrm{~mm}$, which may point to a systematic scale error. In order to examine this possibility, the point cloud of the $1^{\text {st }}$ horizontal section determined inside the developed application was compared to the point cloud of the conventionally measured section. But, in this case most of the comparable distances were from $8 \mathrm{~mm}$ to $40 \mathrm{~mm}$. This leads to the assumption that there is no systematic scale error and the frequency of the values close to $\pm 9 \mathrm{~mm}$, leads to the assumption that a systematic error is introduced when the line trace hits the surface of the 3D model.

As shown in Table 1, the values of the arithmetic means are close to zero, except for the mean of the $1^{\text {st }}$ vertical internal section, which is $1 \mathrm{~mm}$, in absolute value. Thus, the values of the distances are normally distributed and there are no outliers or significant systematic errors detected. Furthermore, the values of the standard deviations of the sections range from $7 \mathrm{~mm}$ to $9 \mathrm{~mm}$, with the $2^{\text {nd }}$ horizontal section's values being higher, while most of the vertical sections have lower values, compared to the horizontal ones. So, the results show deviations within the scale threshold, i.e., less than $20 \mathrm{~mm}$ for the scale of 1:50. Regarding the values of the standard deviations of the external and the corresponding internal sections, no statistically significant differences are observed. To conclude, the deviation of each section point measured inside the VR environment from the reference surface is less than $10 \mathrm{~mm}$, which is an acceptable value for performing measurements that do not require high accuracy.

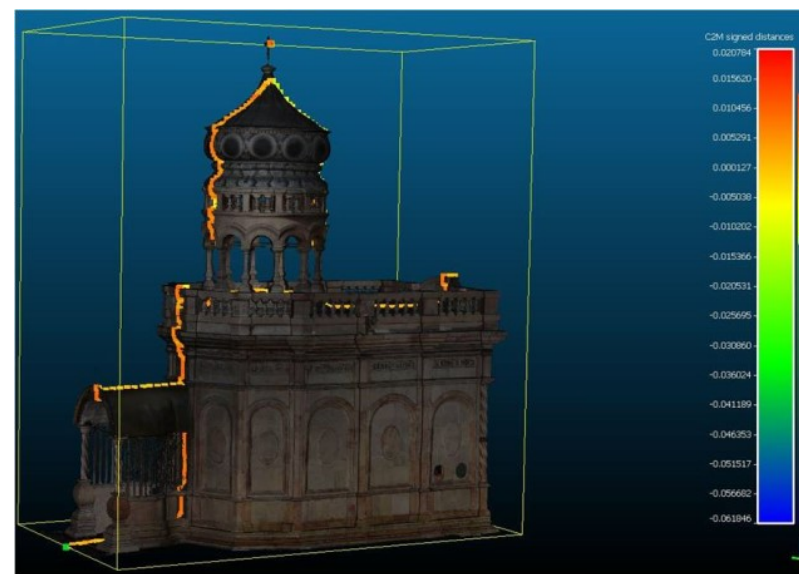

Figure 13: The $2^{\text {nd }}$ vertical section and its deviations from the reference surface

The accuracy of these measurement tools compared to the reference surface has been established to less than $10 \mathrm{~mm}$. Thus, having as reference surface the original three-dimensional model basic measurement work, of supervision, control and study of a three-dimensional object that does not have very high accuracy requirements, can be carried out with sufficient accuracy. This metric error is traced to the coordinate system transformation which takes place as the fixed points have been selected by the user both in the application and in the reference surface and their identification depends on the accuracy of their selection. Although the accuracy with which the application selects and measures three-dimensional coordinates is unknown and may introduce errors throughout the process, the thorough comparison of the cross sections has shown that this fact does not affect the result. Finally, the evaluation process concludes that this is an unprecedented experience for most users who are interested in it. But using it can be improved a lot in order to make the user experience even smoother

\section{CONCLUSIONS}

The development and implementation of the innovative toolbox presented in this paper leads to the general conclusion that the use of virtual reality technology can support many scientific disciplines in many ways and push them towards technological development.

Specifically, engineers related to $3 \mathrm{D}$ data may use this technology as an alternative and, in many cases, more complete method of displaying their data, but also as a means to interact with them when using the right tools. The depiction of threedimensional models in a virtual reality environment is very realistic, which is not the case with other two- or threedimensional imaging methods. In addition, virtual reality technology can contribute to the study of cultural heritage, to its preservation and its promotion.

It has been shown that the developed VR measuring tool is capable of extracting 3D measurements, i.e., 3D coordinates of single points, 3D distances and horizontal or vertical sections at specified horizontal and vertical planes from 3D models, in a very simple manner. Thus, it constitutes a valuable tool for nonexperts, i.e., architects, archaeologists etc., to get these 3D measurements at will without the need to learn a complicated piece of software. The uncertainty of the measurements corresponds to the density and accuracy of the 3D model inserted and it has been proven that the VR measuring toolbox fully exploits the qualities of the data.

Using the 3D model of the Holy Aedicule as an object to be measured, which is a very detailed and accurate model, it is concluded that the application can work with any 3D model and the only limitation in its import are the capabilities of each computer that supports the whole system.

\section{REFERENCES}

Aiello, D., Fai, S., \& Santagati, C. (2019). Virtual Museums as a means for promotion and enhancement of Cultural Heritage. International Archives of the Photogrammetry, Remote Sensing and Spatial Information Sciences - ISPRS Archives, 42(2/W15), 33-40. https://doi.org/10.5194/isprs-archives-XLII-2-W15-332019.

Banfi, F., Brumana, R., Stanga, C. 2019. A content-based immersive experience of basilica of Sant' Ambrogio in Milan: From 3d survey to virtual reality. ISPRS Annals of the Photogrammetry, Remote Sensing and Spatial Information Sciences, 42(2/W11), 159-166. https://doi.org/10.5194/isprsArchives-XLII-2-W11-159-2019.

Belen J. F.-P., Morabito, D., Remondino, F., 2017. Access to complex reality-based 3D models using virtual reality solutions, Journal of Cultural Heritage, Volume 23, 2017, pp. 40-48, ISSN 1296-2074, https://doi.org/10.1016/j.culher.2016.09.003.

Bolognesi, C., Aiello, D., 2019. THE SECRETS of S. MARIA DELLE GRAZIE: VIRTUAL FRUITION of AN ICONIC MILANESE ARCHITECTURE. International Archives of the Photogrammetry, Remote Sensing and Spatial Information Sciences - ISPRS Archives 42, 185-192. https://doi.org/10.5194/isprs-archives-XLII-2-W15-185-2019

Borges, M., Symington, A., Coltin, B., Smith, T., Ventura, R., 2018. HTC Vive: Analysis and Accuracy Improvement. IEEE 2018 IEEE/RSJ International Conference on Intelligent Robots 
and Systems (IROS) - Madrid, Spain (2018.10.1-2018.10.5) 2610-2615. doi:10.1109/IROS.2018.8593707

Georgopoulos, A., Lambrou, E., Pantazis, G., Agrafiotis, P., Papadaki, A., Kotoula, L., Lampropoulos, K., Delegou, E., Apostolopoulou, M., Alexakis, M., Moropoulou, A., 2017. Merging Geometric Documentation with Materials Characterization and Analysis of the History of the Holy Aedicule in the Church of the Holy Sepulchre in Jerusalem. Int. Arch. Photogramm. Remote Sens. Spatial Inf. Sci., XLII-5/W1, 487-494, 2017 https://doi.org/10.5194/isprs-archives-XLII-5W1-487-2017.

Jiménez Fernández-Palacios, B., Morabito, D., Remondino, F., 2017. Access to complex reality-based 3D models using virtual reality solutions. Journal of Cultural Heritage 23, 40-48. https://doi.org/10.1016/j.culher.2016.09.003

Kersten, T. P., Tschirschwitz, F., Deggim, S., \& Lindstaedt, M. 2018a. Virtual reality for cultural heritage monuments - from 3D data recording to immersive visualisation. In Lecture Notes in Computer Science (including subseries Lecture Notes in Artificial Intelligence and Lecture Notes in Bioinformatics): Vol. 11197 LNCS. Springer International Publishing. https://doi.org/10.1007/978-3-030-01765-1_9.

Kersten, Thomas Peter, Tschirschwitz, F., Lindstaedt, M., Deggim, S., 2018b. The historic wooden model of Solomon's Temple: 3D recording, modelling and immersive virtual reality visualisation. Journal of Cultural Heritage Management and Sustainable Development 8, 448-464. https://doi.org/10.1108/JCHMSD-09-2017-0067

Kontos D., Georgopoulos, A., 2020. Performing 3D Measurements in a VR Environment. Int. Arch. Photogramm. Remote Sens. Spatial Inf. Sci., XLIII-B2-2020, 863 870, https://doi.org/10.5194/isprs-archives-XLIII-B2-2020-8632020.

Kreylos, O. 2016. Lighthouse Tracking Examined. http://docok.org/?p=1478 (last visit 24.04.2020)

Moropoulou, A., Georgopoulos, A., Korres, M., Bakolas, A., Labropoulos, K., Agrafiotis, P., Delegou, E. T., Moundoulas, P., Apostolopoulou, M., Lambrou, E., Pantazis, G., Kotoula, L., Papadaki, A. 2017a. Mixed Reality and Gamification for Cultural Heritage. Mixed Reality and Gamification for Cultural Heritage, 247-270. https://doi.org/10.1007/978-3-319-49607-8.

Moropoulou, A., Georgopoulos, A., Korres, M., \& Spyrakos, C. 2017b. Faithful Rehabilitation of the Holy Tomb of Christ. Civil Engineering Magazine, 87 (10-November 2017). https://doi.org/10.1061/ciegag.0001244.

Kersten, T. P., Tschirschwitz, F., Lindstaedt, M., Deggim, S., 2018. The historic wooden model of Solomon's Temple: 3D recording, modelling and immersive virtual reality visualisation. Journal of Cultural Heritage Management and Sustainable Development, 8(4), 448-464. https://doi.org/10.1108/JCHMSD09-2017-0067.

Scianna, A., Gaglio, G. F., Grima, R., La Guardia, M., 2020. The virtualization of $\mathrm{CH}$ for historical reconstruction: the $\mathrm{AR}$ fruition of the fountain of St. George square in Valletta (Malta). International Archives of the Photogrammetry, Remote Sensing and Spatial Information Sciences - ISPRS Archives, 44(4/W1), 143-149. https://doi.org/10.5194/isprs-archives-XLIV-4-W12020-143-2020

Walmsley, A., Kersten, T. P., 2019. Low-cost development of an interactive, immersive virtual reality experience of the historic city model stade 1620. International Archives of the Photogrammetry, Remote Sensing and Spatial Information Sciences - ISPRS Archives, 42(2/W17), 405-411. https://doi.org/10.5194/isprs-archives-XLII-2-W17-405-2019. 